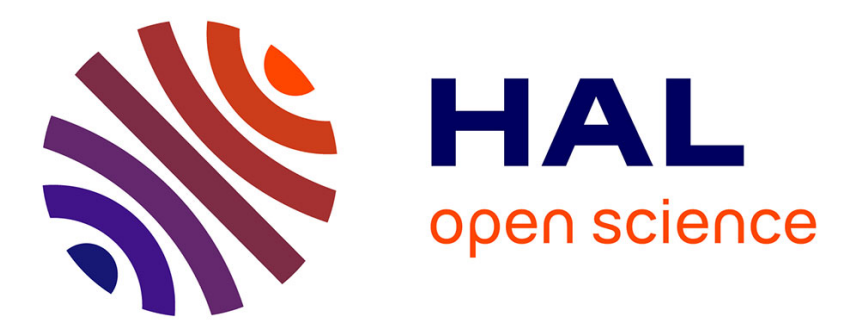

\title{
On the resolution of regional archaeomagnetism: Untangling directional geomagnetic oscillations and data uncertainties using the French archaeomagnetic database for between 1000 and $1500 \mathrm{AD}$ as a guide Maxime Le Goff, Yves Gallet
}

\section{- To cite this version:}

Maxime Le Goff, Yves Gallet. On the resolution of regional archaeomagnetism: Untangling directional geomagnetic oscillations and data uncertainties using the French archaeomagnetic database for between 1000 and $1500 \mathrm{AD}$ as a guide. The Geological Society, London, Special Publications, 2019, 497 (1), pp.113-126. 10.1144/SP497-2019-32 . hal-03028633

\section{HAL Id: hal-03028633 \\ https://hal.science/hal-03028633}

Submitted on 27 Nov 2020

HAL is a multi-disciplinary open access archive for the deposit and dissemination of scientific research documents, whether they are published or not. The documents may come from teaching and research institutions in France or abroad, or from public or private research centers.
L'archive ouverte pluridisciplinaire HAL, est destinée au dépôt et à la diffusion de documents scientifiques de niveau recherche, publiés ou non, émanant des établissements d'enseignement et de recherche français ou étrangers, des laboratoires publics ou privés. 
1 On the resolution of regional archaeomagnetism: Untangling directional

2 geomagnetic oscillations and data uncertainties using the French archaeomagnetic database for between 1000 and 1500 AD as a guide Maxime Le Goff \& Yves Gallet Université de Paris, Institut de Physique du Globe de Paris, CNRS, Paris, France

\section{Abstract}

A complexity is emphasised in the distribution of the French archaeomagnetic directions during the 13th and the 14th centuries AD. Data uncertainties, and the smoothing introduced when estimating an average secular variation curve prevent of century-scale geomagnetic field variations.

scrutiny of the very nature of this complexity. It might correspond to a directional yaw, the nature of which would be compatible with the recent geomagnetic field evolution as traced by the gufm1 model. In order to emphasise this indeterminacy, a reference secular variation curve was constructed for between 1000 and 1500 AD, including the yaw in question, and synthetic databases that mimic the accuracy and density characteristics of the true French archaeomagnetic database were considered for some of these. The synthetic curves hence obtained show that the dating accuracy of archaeomagnetic data is the crucial parameter for constructing a detailed secular variation path. The significant impact of the experimental data accuracy is also illustrated. Even more crucial is the fact that precision of the data dating required to describe the directional variability over the century timescale largely exceeds the precision of the archaeological dates available for the structures generally studied. This highlights the intrinsic limitation of archaeomagnetism for regional reconstruction 
Magnetisation measurements carried out on fired archaeological structures, such as kilns and hearths, found in situ over a more or less extensive region, allow the construction of millennial-scale records of geomagnetic directional secular variation (DSV). Crucial parameters for such reconstructions are the dating of the studied structures -in this case, the dating of their last firing- and the precision of the archaeomagnetic directions determined. Together with archaeointensity determinations, all these results make up the archaeomagnetic database for a given region. With the strong development of archaeomagnetism worldwide in the past two decades, DSV curves have been proposed for different regions, most of them being only located in Europe (e.g. Gallet et al., 2002; Gómez-Paccard et al., 2006; Tema et al., 2006; Hervé et al., 2013; Batt et al., 2017). A discussion of the reliability of the statistical methods used for their construction was not the objective of the present study. Instead, its aim was more from the perspective of the experimenter, in wondering whether an archaeomagnetic dataset is able to accurately constrain and reproduce all the complexity of the regional DSV.

This study arose from our attempts to update the French DSV reference curve for the last two millennia, following a significant increase in the number of data collected by our laboratory since those published in Thellier (1981) and Bucur (1994). Despite a regular overall refinement, there still exists a recurrent complexity around the 13th-14th centuries that manifests itself as a greater dispersion of individual archaeomagnetic directions, that is, those obtained at the level of the different burned structures. It may be recalled that, at a time when archaeomagnetic results were still relatively rare, Aitken (1970) and Clark et al (1988) drew a loop in the British DSV of this period. Similarly, Bucur (1986) proposed a complexity with a 'V' shape in the French curve. On the other hand, more recent DSV curves estimated for France and 
neighbouring countries appear to have favoured a more regular path (for example Bucur, 1994; Le Goff et al., 2002; Batt et al. 2017). Independently, Pavón-Carrasco et al. (2011) emphasised the need for precisely dated results for between 1100 and $1400 \mathrm{AD}$, based on a statistical analysis of the European database.

Based on the observations made above, the question arises of the extent to which a set of archaeomagnetic data is able to reveal loops, hooks or laces in a DSV path. Because of the non-dipole field component, the gufm1 model (Jackson et al., 2000) shows, over the last three centuries, highly variable geomagnetic field evolutions at the latitude of Paris around the Earth (north and south), with large or reduced fluctuations, with or without loops or hooks (Fig. 1; see also Thompson \& Barraclough, 1982). For example, the large, almost semicircle well-known in Western Europe (e.g. Le Goff and Gallet, 2017), with a length of $\sim 17^{\circ}$ (a, Fig. 1) is reduced to a yaw of $\sim 11^{\circ}$ in eastern Canada (b, Fig. 1), to a $\sim 5^{\circ}$ linear segment in the Aleutian Islands (c, Fig. 1) or a loop towards the Prince Edward Islands in the Southern Hemisphere (d, Fig. 1). It is safe to consider that these various paths of the local DSV, observed at the same time in different places, may also have occurred at the same place over past centuries. Given the characteristics of an archaeomagnetic database -that is, the precision and density of the data available over time- would such fluctuations be recovered, and how?

To our knowledge, the preliminary question of the precision of the archaeodirectional results necessary to recover an accurate DSV evolution has not been fully debated, with regard to the known complexity of the geomagnetic field. In this study, we have chosen to illustrate this question empirically by constructing synthetic databases from a tortuous, but realistic, DSV path, and from the concrete case of the French archaeomagnetic database currently available for between 1000 and 1500 AD. The main objective of this exercise was, therefore, to provide constraints on the 
dating and experimental precision of the archaeomagnetic data that are required to trace a DSV path as accurately as possible.

\section{A possible secular variation path in France for between 1000 and 1500 AD}

\section{Description of the French archaeomagnetic database}

It is worth pointing out that the purpose of this study was not to describe new archaeomagnetic data obtained in France, but rather to highlight the global characteristics of such data (number, precision of their determination and dating). First, however, we briefly recall some information related to their acquisition.

The data considered in this study were obtained using the experimental method developed by Emile Thellier (e.g. Thellier, 1981). The samples were collected using the so-called plaster cap method, which allowed them to be precisely oriented with respect to the geographic north. These samples were extracted from decimetre-sized blocks of baked clay, taken from the best-preserved parts of the structures and consolidated with plaster strips to ensure their cohesion during sampling and subsequent preparation in the laboratory. After sawing in the laboratory, each sample associated with a plaster cap bearing its orientation was embedded in plaster according to a standard format, with a square base of $12 \mathrm{~cm}$ on each side. The remanent magnetisation was measured in the palaeomagnetism laboratory at Saint-Maur (Institut de Physique du Globe de Paris) using an inductometer especially designed for large samples (Le Goff, 1975).

In the case of fired archaeological structures, the remanent magnetisation of the samples is generally the simple superposition of a thermal remanent magnetisation (TRM) acquired during cooling following the last heating of the structure and a viscous remanent magnetisation (VRM) (e.g. Thellier, 1981; Dunlop 
and Özdemir, 1997). To estimate the importance of the VRM relative to the TRM, and to largely remove its effect, the samples were kept for several weeks (at least one month) in a position parallel to the direction of the ambient geomagnetic field. After this interval of time, the remanent magnetisation of the samples was measured for the first time. The samples were then placed in a position reversed with respect to that of the ambient field and again left for several weeks. A second measurement of their remanent magnetisation then made it possible to estimate, by vector subtraction, the importance for each sample of the VRM relative to the TRM (and its direction), as well as the TRM direction. Samples with viscosity rates (expressed by the VRM/TRM ratio, in \%) that were too high (>12\%) were eliminated because their TRM direction might be slightly biased by a certain fraction of VRM (although, in fact, the magnetic viscosities rarely exceeded $12 \%$ ).

For the first five centuries of the second millennium AD (central dates between 1000 and $1500 \mathrm{AD}$ ), the currently available French database comprises 113 directional data-points, distributed irregularly, and corresponding to an average of about 23 results per century. Among these data, 59 were described by Bucur (1994), including those of Thellier (1981), while 54 data were acquired over the last 25 years, and have not yet been published.

Figure 2 presents the angular $\left(\alpha_{95}\right)$ and dating $(\Delta t)$ uncertainties of all the directions contained in the currently available French database. Concerning the directional accuracy (Fig. 2a), $\sim 90 \%$ of the data are defined with $\alpha_{95}$ values $<2.0^{\circ}$, while $\sim 70 \%$ of the data have $\alpha_{95}$ values $<1.5^{\circ}$. Only $\sim 5 \%$ of the data have $\alpha_{95}$ values $>3.0^{\circ}$. On average, the mean $\alpha_{95}$ for the archaeomagnetic directions of the French database for between 1000 and $1500 \mathrm{AD}$ amounts to $\sim 1.3^{\circ}$. Concerning the age uncertainties (Fig. $2 b$ ), $\sim 75 \%$ of the data have a date known to lie within a time interval of 200 years ( $\Delta t=100$ years). This proportion decreases to $\sim 60 \%$ for a time 
interval of 150 years ( $\Delta t=75$ years) and to $\sim 35 \%$ for a time interval of 100 years

$130(\Delta t=50$ years). For this study, we chose to eliminate seven data-points with $\Delta t$ values

$131>150$ years (i.e. age ranges $>300$ years). For the remaining 106 data-points, the dating interval of the available results has a mean duration of $\sim 110$ years $(\Delta t=55$ years).

\section{Estimated and schematised DSV curve}

The set of 106 archaeomagnetic directions was reduced to a single site, here Paris (Latitude $48.9^{\circ} \mathrm{N}$, Longitude $2.3^{\circ} \mathrm{E}$ ), using the virtual geomagnetic poles. Figure 3 shows all the declination and inclination data after their reduction to Paris. These data were then used to estimate an average secular variation curve, using the method that relies on sliding windows of variable durations developed by Le Goff et al. (2002). The duration of each window was automatically adjusted, following the temporal distribution of the available data, by fixing a minimum density (or weight) of the data in each window (here eight), each datum being weighted by the portion of time intercepted in the window. The minimum duration of the windows was set at 20 years. The windows followed one another with a minimum step of half the duration of the previous (older) one (see discussion in Le Goff et al., 2002). The mean directions of the different time windows were estimated using the bivariate extension of Fisher's (1953) statistics (see Le Goff, 1990; Le Goff et al. 1992). This method, which illustrates the DSV path as a succession of ovals, is particularly well suited to the problem of secular variation because, in the ideal case of almost no directional and temporal uncertainties, the elongation of each oval is an indicator of the drifting direction of the geomagnetic field through the course of the window's duration. When placed over a longer segment of the DSV curve (i.e. over several centuries), it is therefore expected that the elongation directions of the ovals correspond to the 
drifting directions of the geomagnetic field. Conversely, a transverse elongation, with respect to the geomagnetic evolution, or even small elongations over a segment of the curve with a significant directional evolution, can be seen as either reflecting a problem in the data for the considered period or indicative of geomagnetic complexity during this period.

Such complexity was observed around the second half of the 13th century AD in the secular variation paths obtained by Bucur (1994) and Le Goff et al (2002), both studies relying on the same data selection, but with the use of sliding windows of the same duration (80 years) in the former and of variable durations in the latter (with a minimum weight of 2.5 and a minimum duration of 20 years). These DSV paths were estimated only on the basis of data reliably dated by the archaeologists (referred to as 'PC' in Bucur, 1994), thus retaining less than half the available results (i.e. 26 data-points between 1000 and $1500 \mathrm{AD}$, instead of the 57 results considered in the present study). We also retained the data dated with less certainty by the archaeologists, as they asked for confirmation of the archaeological dating using archaeomagnetism (note that only the archaeological dating was retained). All individual archaeomagnetic directions were obtained with the same care and, whatever their dating, they equivalently represent the direction of the geomagnetic field that prevailed when the magnetisation was acquired in the baked clay.

Logically (and ideally), the representation of directions on a spherical diagram should draw the path of the DSV, which would then only need to be anchored in time. This is fortunately what can be observed in Fig. 4, which illustrates all the directions, with the confidence ovals depicting a relatively coherent evolution, despite some clearly identifiable remote data. In this figure, the DSV curve was estimated using a minimum weight of 8 and a minimum duration of 20 years for each time window. Note that the choice of the weight was rather delicate (and so could be challenged), but 
181 the value used gives enough detail (about five windows per century) without 182 oversmoothing the DSV evolution. In order to better illustrate this point, black and white bars, marking both the direction and ellipticity (the length of the bars) of the ovals, have been added to Fig. 4 at the centres of the different confidence ovals. We observe that, in the time interval between the 13th and 14th centuries, unlike the intervals before and after, the elongation of the confidence ovals does not follow the geomagnetic directional drift. This time interval, however, is not marked by an absence of directional variations. This remark is further illustrated in Fig. $5 a, b$, in which two directional branches (between 1000 and 1350, and between 1350 and 1500) are separately shown, the first being characterised by decreasing inclinations (Fig. 5a), and the second by increasing inclinations (Fig. 5b). In these two diagrams, each individual direction is recorded by a diamond, oriented along the tangent to the curve taken at its central date (here, the curve was estimated using a weight of 10), coloured according to the age range assigned by an archaeologist (see colour code on the figure). The distribution of the directions shows that the 13th century period is characterised by more scattered data than the other periods, in a direction transverse to the overall evolution of the secular variation (double arrow, Fig. 5a). Similarly, there is more scatter in the inclinations of directions dated around the end of the 14th century (Fig. 5b), where a directional kink occurs (Bucur, 1994; Le Goff et al., 2002), with individual inclinations around 1380 AD in particular being significantly lower than those of the mean curve (thick white arrow, Fig. 5b).

Because of the absence of archaeological arguments allowing the rejection or correction of individual archaeomagnetic directions dated from the 13th and 14th centuries $A D$, which could have resulted from a slight tilting of the structures due to soil compaction, for example, or could have been affected by poorly-established dating, it appears, from the previous observations, that the 'true' secular variation 
207 path during this time interval might be significantly more complex than the simple and 208 large directional curvature observed between about 800 AD and 1400 AD (Fig. 4; see 209 also Bucur, 1994; Le Goff et al., 2002). The uncertainties associated with the 210 available archaeomagnetic data and those related to the temporal smoothing induced 211 by the computation of the reference DSV curve (as is also the case for all other 212 methods developed so far) make it so that there is no statistical tool available to 213 robustly reveal the exact nature of this (still potential) complexity. The latter should nevertheless be included in the $95 \%$ confidence intervals of the reference curve. The only way to achieve this is to empirically and approximately estimate it in such a way that as many individual archaeomagnetic directions as possible lie close to a segment of the secular variation path.

In our study, we thus constructed (by hand) a yaw during the 13th and 14th centuries AD (green curve, Fig. 6), somewhat similar to that previously proposed by Bucur (1986, which was also built manually), which is discussed below. This yaw was obtained by stretching the mean DSV curve using Bézier curves. This is a reasonable solution, but it could just as easily be a loop. In both cases, these evolutions are as possible, in terms of amplitude and duration of variations, as those based on the constraints provided by the gufm1 model (see examples in Fig. 1). Note that this indeterminacy is not critical to the subject of this study.

\section{Method used to analyse the sensitivity of a database}

Our approach aimed to illustrate how the accuracy of the reconstruction of the secular variation path was conditioned by: (i) the precision parameters in the 230 direction and age of the individual archaeomagnetic data, and (ii) the parameters of abundance, distribution and temporal homogeneity of the relevant dataset. 
To do this, synthetic databases were extracted from the reference DSV curve 233 that included the geomagnetic complexity discussed in the previous section. This consisted of taking sets of directions with realistic age intervals and directional accuracies (i.e. based on those from the available database), or that were arbitrarily fixed. The number of data and their temporal distributions for each dataset were two other parameters that could be adjusted. Synthetic databases were constructed in several ways, by taking directions (declinations, inclinations) from a number of dates existing in the real database (i.e. having the same mean ages), or from a number of dates that were regularly or randomly distributed, to which dating and experimental uncertainties were assigned, either according to the real database, or in a homogeneous way (i.e. with fixed and constant parameters). The first option based on the French, as well as the British, database, was the most realistic case. Other 'ideal' databases were composed of directional data all having identical $\alpha_{95}$ and $\Delta t$ evenly distributed over the 500-year interval.

From these synthetic databases, renewed by random draws, DSV curves were calculated by setting, in advance and once and for all, the minimum density of the data in each self-adjusting time window. With a few dozen draws of datasets, a distribution of curves and an average curve were obtained that could then be directly compared to the original DSV curve. In the tests described in the next section, we started with initial parameters close to those of the French database for between 1000 and $1500 \mathrm{AD}$ (without the data with $\Delta \mathrm{t}>150$ years). We then carried out computations using the characteristics of the British database, with only English and Welsh data, from the same time interval (Fig. S1). The two databases differed in their mean $\alpha_{95}\left(1.3^{\circ}\right.$ for the French database, $3.2^{\circ}$ for the British database $)$ and the number of data (about 20 results per century, on average, for the French database, 


\section{Results of the synthetic tests}

260

261

262

263

264

\section{Effect of dating and experimental uncertainties}

The first series of computations relied on the same number (106) of directions, and on the exact same time distribution to those of the French data for between 1000 and $1500 \mathrm{AD}$. The synthetic data were produced using a uniform random drawing of a date in each of the dating ranges of the true data, and determination of mean directions derived from the reference DSV curve at the dates previously obtained, randomly drawn from Gaussian distributions within the radius confidence circles $\alpha_{95}$ of the true directions at the considered time intervals. The corresponding $\alpha_{95}$ values and age ranges were then assigned to these new directions. We could thus scrutinise the impact on the reliability of the recalculated curve of an overall improvement or degradation of the parameters $\alpha_{95}$ and $\Delta t$, by applying a multiplicative factor of $<$ or $>1$, respectively.

The results in Fig. 7 are reported in two different ways. First, their spherical projection (upper panels) gives a direct view of the synthetic curves (in blue), their variability and of their average behaviour (curve in yellow). Second, results are also presented using a more quantitative approach by considering the mean angular departures of the synthetic curves from the reference DSV path as a function of time (lower panels). Note that positive and negative values refer to mean departures outside and inside the reference curve. Fig. 7a shows that the realistic yaw introduced into the secular variation curve was practically smoothed out by the process of calculating the mean directions. More generally, only a small inflection is observable around $1250 \mathrm{AD}$, as is also the case when the computations are carried out using the exact parameters of the real French archaeomagnetic database (green- 
283 white curve in Fig. 6). Similarly, the extremity of the directional kink at around 1350 284 AD was almost never reached. These differences lead to significant mean angular 285 departures up to $2^{\circ}$ between the synthetic curves and the reference curve. The $\Delta t$ values had to be significantly reduced (by a factor of five), until they reached an 287 average of 11 years $(0<\Delta t<30$ years $)$, to faithfully and almost systematically reproduce the western extremity of the yaw, but the short undulation around $1200 \mathrm{AD}$ remained undetected (Fig. $7 \mathrm{~b}$ ). When the $\alpha_{95}$ values were chosen to be higher on average (value of $3.0^{\circ}$ ), the directional curves appeared more scattered and irregular (Fig. 7c,d). Their average (Fig. 7) led to the same observations as previously, but the most important element here is the variability between the individual curves, each estimated using a selected dataset. We observed that increasing the $\alpha_{95}$ mean value can result in a curve rather different from the reference path, even when a mean $\Delta t$ of 11 years was considered (Fig. $7 \mathrm{~d}$ ). To first order, this observation is also attested by the averaging of the one-sigma errors of the angular departures estimated for between $1000 \mathrm{AD}$ and $1500 \mathrm{AD}$ : (a) $0.34^{\circ}$, (b) $0.30^{\circ}$ (c) $0.62^{\circ}$, (d) $0.68^{\circ}$. This illustrates the fact that, although the impact of age-related uncertainties on the reliability of the estimated secular variation curve is strong, the impact of experimental errors cannot be neglected either.

In a second series of computations (Fig. S2), we showed that the previous observations remained unchanged when the time distribution and number (145) of 303 the English and Welsh archaeomagnetic data were considered (Batt et al., 2017). The only difference concerns the undulation around 1200 AD, which appeared to be better resolved with a mean $\Delta \mathrm{T}$ of 11 years than in the French case, but only when the directional accuracy was decreased on average to $1.0^{\circ}$, thus close to the French 307 value (Fig. S2d). This also underlines the effects due to the number and age distribution of the data (see below) 
Version du 12/08/2019

We then considered a more idealised situation with, on the one hand, a uniform distribution of the mean dates of the data over 500 years and, on the other hand, constant values of $\alpha_{95}$ and $\Delta t$ for all data. In a first case, we considered a distribution of 170 data, or 34 data per century (Fig. 8). When all $\Delta$ t were 55 years, the yaw in the secular variation was completely smoothed out, whether the $\alpha_{95}$ values were fixed at $1.3^{\circ}$ (Fig. 8a) or $3.0^{\circ}$ (Fig. 8c). As in the previous calculations, the $\Delta t$ had to be reduced by a factor of five to reveal the complexity in the secular variation path, including the undulation around 1200 AD. In the same way, Fig. 8c,d also indicates that a better data accuracy increases the reliability of the DSV reconstructions (note that the averaged one-sigma errors of the angular differences are: (a) $0.30^{\circ}$, (b) $0.25^{\circ}$, (c) $0.41^{\circ}$, (d) $0.55^{\circ}$ ).

\section{Effect of data density}

To illustrate this aspect, an idealised situation was again considered, with a uniform temporal distribution of the data, but varying their number between 170 and 50 , and by fixing their mean $\alpha_{95}$ and $\Delta t$ at $1.3^{\circ}$ and 11 years, respectively. The first case with 170 values was identical to the one shown in Fig. 8b, where the yaw in the secular variation path is accurately depicted (Fig. 9a). When this number was reduced to 100 values (20 data per century), the yaw was always observable but its amplitude was less than that of the reference curve (Fig. 9b). By reducing the number to 50 data (Fig. 9c), i.e. 10 data per century, the yaw became completely hidden, and most of curves showed a smooth evolution similar to that observed when considering the parameters of the French archaeomagnetic database (106 data, with a variable temporal distribution of the data, a mean $\alpha_{95}$ of $1.3^{\circ}$ and a mean $\Delta t$ of 55 years). This indicates that, in this case, the number of data and the values of $\Delta t$ acted 
334 in a very similar way on the recovery of the secular variation path. As before, Fig. 9d

335 further shows that this observation was not fundamentally modified when the accuracy of the individual data was reduced (with a mean $\alpha_{95}$ of $3.0^{\circ}$ ). As previously, 337 the accuracy of the data had an impact on the regularity and variability of the 338 individual curves, more than on the overall evolution of the secular variation that the 339 curves collectively defined (yellow curve in Fig. 9c,d).

\section{Discussion and concluding remarks}

The present study involved an experimental illustration to demonstrate the characteristics that an archaeomagnetic database should possess to recover detailed directional variations of the regional geomagnetic field. Our synthetic tests underlined the fact that the crucial parameter for constructing a detailed secular variation curve is the precision in the dating of the data. Although less critical, the experimental data accuracy (defined by a mean $\alpha_{95}$ ) has nevertheless a significant and obvious impact on the reliability and precision of DSV reconstructions.

Another fundamental element is the intrinsic limitation of archaeomagnetism for DSV reconstruction. Using the gufm1 historical geomagnetic field model (Jackson et al. 2000), which in our case provided realistic information on possible secular variation paths, we showed that the dating accuracy of the archaeomagnetic data required to describe the directional variability, largely and very generally exceeded the accuracy of the archaeological dates available for the studied archaeological structures (i.e. the dating of the last use of the kilns). A dating accuracy of $\sim+/-10$ years, on average, for the archaeomagnetic data appeared necessary to correctly recover the directional geomagnetic field variations. More in detail, however, it should 
still not allow the recovery of a short undulation like the one simulated around 1200 $A D$ mainly because of the age distribution of the available data. In any case, this dating precision is not realistic, given the possibilities offered by archaeology. Furthermore, our synthetic tests also indicated that a larger number of data would not compensate for and/or significantly improve the reconstructions based on results that were not precisely dated (even with a mean $\Delta t$ of $\sim 50$ years; Fig. 9).

From our tests, we found that, given the nature of the archaeomagnetic data used to calculate a mean secular variation curve (i.e. a process that necessarily generates a temporal smoothing), it is very difficult if not impossible to precisely constrain the secular variation path that may have occurred over a timescale of one or two centuries. The apparent absence of geomagnetic complexity observed over this timescale does not prejudge its actual absence or occurrence. In other words, our knowledge of the regional secular variation, based on archaeomagnetic data, is necessarily limited, with an incompleteness that cannot be estimated, even if the data are precisely experimentally determined and available in large numbers (several dozen data-points per century). Our study, nevertheless, indicates that the use of the bivariate Fisher statistics for constructing secular variation curves (Le Goff et al., 1992; 2002) gives some clues about possible undetected, rapid directional fluctuations.

These findings should not be seen as a negative surprise (see discussion in Pavón-Carrasco et al., 2011). Our tests have mainly illustrated a situation that is often neglected, and which is not without echo with the spatial and temporal resolution of the global archaeomagnetic field reconstructions (e.g. Hongre et al., 1998; Korte et al., 2009 and references therein). Licht et al (2013) and Sanchez et al (2016) showed that, given the precision of the data and their spatial and temporal distributions, the global archaeomagnetic database (including both archaeological 
and volcanic data) available for the last three millennia does not allow reliable global field reconstructions beyond spherical harmonics of degree 4-5. Note that this corresponds to the optimal case, for which there are no outliers in the archaeomagnetic database, otherwise the resolution would be less. It seems likely that Gauss coefficients > degree 3-4 could generate fluctuations of the same nature as the yaw analysed in our study, which would provide first-order information on the geomagnetic resolution of regional archaeomagnetism.

Finally, the implications of our results on the archaeomagnetic dating method should be stressed (see also discussion in Le Goff et al., 2002 and Pavón-Carrasco et al., 2011). This method is based on a reference secular variation curve that is therefore limited in resolution, and is possibly incomplete. The basic principle of an archaeomagnetic dating relies on the comparison between a snapshot of the geomagnetic field (as provided by an individual archaeomagnetic direction) revealing all its possible complexity, and a smoothed secular variation curve, the error bars of which give relatively little information on the detailed, century-scale secular variation path. This leads to the ambiguities inherent in the archaeomagnetic dating method, which require further methodological developments that exceed the aim of the present study.

\section{Acknowledgements}

We are very grateful to Nicolas Warmé and Agnès Genevey who contributed to the acquisition of new archaeomagnetic data in France since lleana Bucur's retirement, and for daily discussions. We also thank Javier Pavón-Carrasco and Pierre Camps for helpful comments on the manuscript. This study was partly supported by the Simone and Cino Del Duca Foundation of the French Academy of Science. IPGP contribution no. 4059. 


\section{References}

413 Aitken, M. J., 1970. Dating by archaeomagnetic and thermoluminescence methods.

414 Phil. Trans. R. Soc. Lond. Ser. A 269, 77-881970

415 Batt, C., Brown, M. C., Clelland S.-J., Korte, M., Linford, P., Outram, Z., 2017. 416 Advances in archaeomagnetic dating in Britain : New data, new approaches and a 417 new calibration curve. J. Archaeo. Sci. 85, 66-82.

418 Bucur, I., 1986. Fourteenth century archaeomagnetoc field directions from widely 419 distributed sites in France. Proceedings of the 24th International Archaeometry 420 symposium, Olin J. S. and Blackman M. J. Eds, Smithsonian Institution Press, 421 Washington D.C., 449-458.

422 Bucur, I., 1994. The direction of the terrestrial magnetic field in France during the last 42321 centuries. Phys. Earth Planet. Inter. 87, 95-109.

424 Clark, A., Tarling, D., Noël, M., 1988. Developments in archaeomagnetic dating in 425 Great Britain. J. Archaeol. Sci. 15, 645-667.

426 D. Dunlop, D., Özdemir, Ö., 1997. Rock Magnetism, Fundamental and Frontiers. 427 Cambridge University Press, $573 \mathrm{p}$.

428 Fisher, R. A., 1953. Dispersion on a sphere. Proc. R. Soc. Lond. Ser. A 217, 295429305.

430 Gallet, Y., Genevey, A., Le Goff, L., 2002. Three millennia of directional variation of 431 the Earth's magnetic field in western Europe as revealed by archaeological artefacts. 432 Phys. Earth Planet. Inter. 131, 81-89.

433 Gómez-Paccard, M., Chauvin, A., Lanos, P., Mclntosh, G., Osete, M. L., Catanzariti, 434 G., Ruiz-Martınez, V. C., Nunez, J. I., 2006. First archaeomagnetic secular variation 
435

436

437

438

439

440

441

442

443

444

445

446

curve for the Iberian Peninsula: Comparison with other data from Western Europe and with global geomagnetic field models. Geophys. Geochem. Geosyst. 7, 12.

Hervé, G., Chauvin, A., Lanos, P., 2013. Geomagnetic field variations in Western Europe from 1500 BC to 200 AD. Part I: directional secular variation curve. Phys. Earth Planet. Inter. 218, 1-13

Hongre, L., Hulot, G., Khokhlov, A., 1998. An analysis of the geomagnetic field over the past 2000 years. Phys. Earth Planet. Inter. 106, 311-335.

Jackson, A., Jonkers, A., Walker, M., 2000. Four centuries of geomagnetic secular variation from historical records. Philos. Trans. R. Soc. Lond. Ser. A 358, 957-990.

Korte, M., Donadini, C., Constable, C.G., 2009. The geomagnetic Field for 0-3 ka, part II: a new series of time-varying global models. Geochem. Geophys. Geosyst. 10,

$$
\text { Q06008. }
$$

Le Goff, M., 1975. Inductomètre à rotation continue pour la mesure des faibles aimantations rémanentes et induites en magnétisme des roches. PhD Thesis, CNAM Paris, 85p.

Le Goff, M., 1990. Lissage et limites d'incertitude des courbes de migration polaire: pondération des données et extension bivariante de la statistique de Fisher. C. R. Acad. Sci. Sér. II 311, 1191-1198.

Le Goff, M., Henry, B., Daly, L., 1992. Practical method for drawing a VGP path. Phys. Earth Planet. Int. 70, 201-204.

Le Goff, M., Gallet, Y., Genevey, A., Warmé, N., 2002. On archaeomagnetic secular variation curves and archaeomagnetic dating. Phys. Earth Planet. Inter. 134, 203211.

Le Goff, M., Gallet, Y., 2017. A reappraisal of instrumental magnetic measurements 
459 made in Western Europe before AD 1750: confronting historical geomagnetism and 460 archaeomagnetism. Earth Planets and Space 69, 32.

461 Licht, A., Hulot, G., Gallet, Y., Thébault, E., 2013. Ensembles of low degree 462 archaeomagnetic field models for the past three millennia. Phys. Earth Planet. Inter. 463 $224,38-67$.

464 Pavón-Carrasco, J., Rodríguez-González, J., Osete, M. L., Torta, J. M., 2011. A 465 Matlab tool for archaeomagnetic dating. J. Archaeo. Sci. 38, 408-419.

466 Sanchez, S., Fournier, A., Aubert, J., Cosme, E., Gallet, Y., 2016. Modelling the 467 archaeomagnetic field under spatial constraints from dynamo simulations: A 468 resolution analysis. Geophys. J. Int. 207, 983-1002.

469 Tema, E., Hedley, I., Lanos, P., 2006. Archaeomagnetism in Italy: a compilation of 470 data including new results and a preliminary Italian secular variation curve. Geophys. 471 J. Int. 167, 1160-1171.

472 Thellier, E., 1981. Sur la direction du champ magnétique terrestre en France durant 473 les deux derniers millénaires. Phys. Earth Planet. Inter. 24, 89-132.

474 Thompson, R., Barraclough, D. R., 1982. Geomagnetic secular variation based on 475 spherical harmonic and cross validation analyses of historical and archaeomagnetic 476 data. J. Geomag. Geoelec. 34, 245-263.

477 
478

479

480

481

482

483

484

485

486

487

488

489

490

491

492

493

494

495

496

497

498

499

500

501

502

\section{Figure captions}

Fig. 1. Examples of directional segments, curves, loops and yaws over the past few centuries (1700-1990 AD) observed from the gufm1 model (Jackson et al., 2000) for different sites located in the Northern (in blue) and Southern (in brown) Hemispheres at the same latitude as Paris (see details on the figure and in the text). The evolutions from four locations are discussed in the text (double lines): (a) Paris, (b) eastern Canada, (c) Aleutian Islands, (d) Prince Edward Islands. The yellow circle indicates the direction of the axial-dipolar geomagnetic field at the latitude of Paris.

Fig. 2. Description of the 113 directional data-points from the French archaeomagnetic database currently available for between 1000 and 1500 AD. a) Histogram of directional uncertainties $\left(\alpha_{95}\right)$. b) Histogram of age uncertainties $(\Delta t)$. c) Temporal distribution of age intervals of the available data. In red, data reported in Bucur (1994); in blue, new archaeomagnetic data obtained in the laboratory since 1994. Seven results with age uncertainties of $>150$ years (in grey, in the different panels) were discarded.

Fig. 3. Declination (a) and inclination (b) data available from the French archaeomagnetic database for between 1000 and 1500 AD. The declination and inclination averages (green line) were estimated using the Le Goff et al. (2002) method. The associated uncertainties (in grey) are given as values of $\alpha_{95}$ obtained for the different sliding windows.

Fig. 4. Directions dated for between 1000 and 1500 AD from the French archaeomagnetic database and the associated average secular variation curve, estimated using the bivariate Fisher statistics over sliding windows of varying durations (Le Goff et al., 2002) (see text for details). All directions were reduced to 
503

504

505

506

507

508

509

510

511

512

513

514

515

516

517

Paris. A colour code corresponds to the $\alpha_{95}$ values of the individual directions: white, $\alpha_{95} \leq 0.5^{\circ}$; yellow, $0.5^{\circ}<\alpha_{95} \leq 0.9^{\circ}$; peach, $0.9^{\circ}<\alpha_{95} \leq 1.5^{\circ}$; green, $1.5^{\circ}<\alpha_{95} \leq 2.6^{\circ}$; blue, $\alpha_{95}>2.6^{\circ}$. The corresponding circles are superimposed from the largest to the smallest. The $95 \%$ confidence ovals of the average directional curve are shown in transparent white. The lengths of the bars at the centres of the ovals gives the direction and ellipticity of the different ovals.

Fig. 5. Alternative representation of the individual archaeomagnetic directions available for the [1000-1500 AD] time interval. A distinction was made between two periods: (a) 1000 and $1350 \mathrm{AD}$, during which the inclinations decrease, (b) 1350 and $1500 \mathrm{AD}$, during which they increase. Each direction is reported as a diamond oriented along the tangent to the average (blue-white) curve taken at its central date and coloured according to the age range assigned by archaeologists (see colour codes on the figure).

Fig. 6. Estimated and schematised average directional secular variation curves for between $\sim 1000$ and $\sim 1500$ AD. Red/white curve and associated 95\% confidence ovals: secular variation curve estimated using the French archaeomagnetic database (same as in Fig. 4). Green curve: hand-drawn directional evolution, as considered in the present study, which is compatible with both the available data and the expected field variability (see discussion in the text). Green/white curve: mean secular variation curve obtained from a dataset directly given by the green curve itself with the same parameters (experimental and dating uncertainties, number and temporal distributions) as those of the real French archaeomagnetic database (see text).

Fig. 7. Effects of the experimental and age uncertainties on the recovery of the directional secular variation curve. Twenty synthetic datasets were randomly selected from the real French archaeomagnetic database and used to sample the reference secular variation curve that exhibits a directional yaw in the 13th and 14th centuries 
AD. Upper panels: spherical projections of the results and of the reference DSV curve (in green). The red dots show the randomly selected directions of one of the 20 datasets. The directional curves obtained using the Le Goff et al. (2002) method are reported in blue, their average in yellow. (a) Mean $\alpha_{95}=1.3^{\circ}$, mean $\Delta t=55$ years, (b) Mean $\alpha_{95}=1.3^{\circ}$, mean $\Delta t=11$ years, (c) Mean $\alpha_{95}=3.0^{\circ}$, mean $\Delta t=55$ years, (d) Mean $\alpha_{95}=3.0^{\circ}$, mean $\Delta t=11$ years (see text for further explanations). Lower panels: corresponding mean angular departures between the synthetic curves and the reference DSV path. Positive (negative) values indicate when the differences are on average outside (inside) the reference curve. Vertical bars show the one-sigma errors of the mean angular departures.

Fig. 8. Effect of the time distribution of the data on the recovery of the directional secular variation curve. Twenty synthetic sets of 170 data-points with uniform time distribution were considered inside the 1000-1500 AD interval. Constant values of $\alpha_{95}$ $\left(1.3^{\circ} \mathrm{a}-\mathrm{b}\right.$ and $\left.3.0^{\circ} \mathrm{c}-\mathrm{d}\right)$ and $\Delta \mathrm{t}$ (55 years a-c and 11 years $\left.\mathrm{b}-\mathrm{d}\right)$ were considered for each diagram. Same legends as in Fig. 7.

Fig. 9. Effect of the number of data $(\mathrm{N})$ on the recovery of the directional secular variation curve. For each dataset considered, the time distribution of the $\mathrm{N}$ data are uniform inside the 1000-1500 AD interval, and they have constant values of $\alpha_{95}$ and $\Delta \mathrm{t}$ (the latter is 11 years for the four diagrams). Same conventions as in Fig. 7. (a) $\alpha_{95}=1.3^{\circ}, N=170,(b) \alpha_{95}=1.3^{\circ}, N=100$, (c) $\alpha_{95}=1.3^{\circ}, N=50$, (d) $\alpha_{95}=3.0^{\circ}, N=100$.

Fig. S1. Description of the 303 directional results dated between 1000 and 1500 AD obtained from England and Wales (Batt et al., 2017). a) Histogram of experimental uncertainties $\left(\alpha_{95}\right)$. Pale green, all data; dark green, only data with $\Delta t \leq 150$ years. b) Histogram of age uncertainties ( $\Delta \mathrm{t})$ for all available data. Pale green, data with $\Delta \mathrm{t}>$ 
553150 years; dark green, data with $\Delta t \leq 150$ years. c) Temporal distribution of age 554 intervals of the available data with $\Delta \mathrm{t} \leq 150$ years.

555 Fig. S2. Secular variation curves (in blue) obtained from 20 synthetic directional 556 datasets randomly selected from the real British (England and Wales) 557 archaeomagnetic database (Batt et al., 2017). All directions were transferred to the 558 latitude of Paris. (a) Mean $\alpha_{95}=3.2^{\circ}$, mean $\Delta \mathrm{t}=53$ years, (b) Mean $\alpha_{95}=3.2^{\circ}$, mean $559 \Delta \mathrm{t}=11$ years, (c) Mean $\alpha_{95}=1.0^{\circ}$, mean $\Delta \mathrm{t}=53$ years, (d) Mean $\alpha_{95}=1.0^{\circ}$, mean $\Delta \mathrm{t}=11$ 560 years. Same legends as in Fig. 7. 


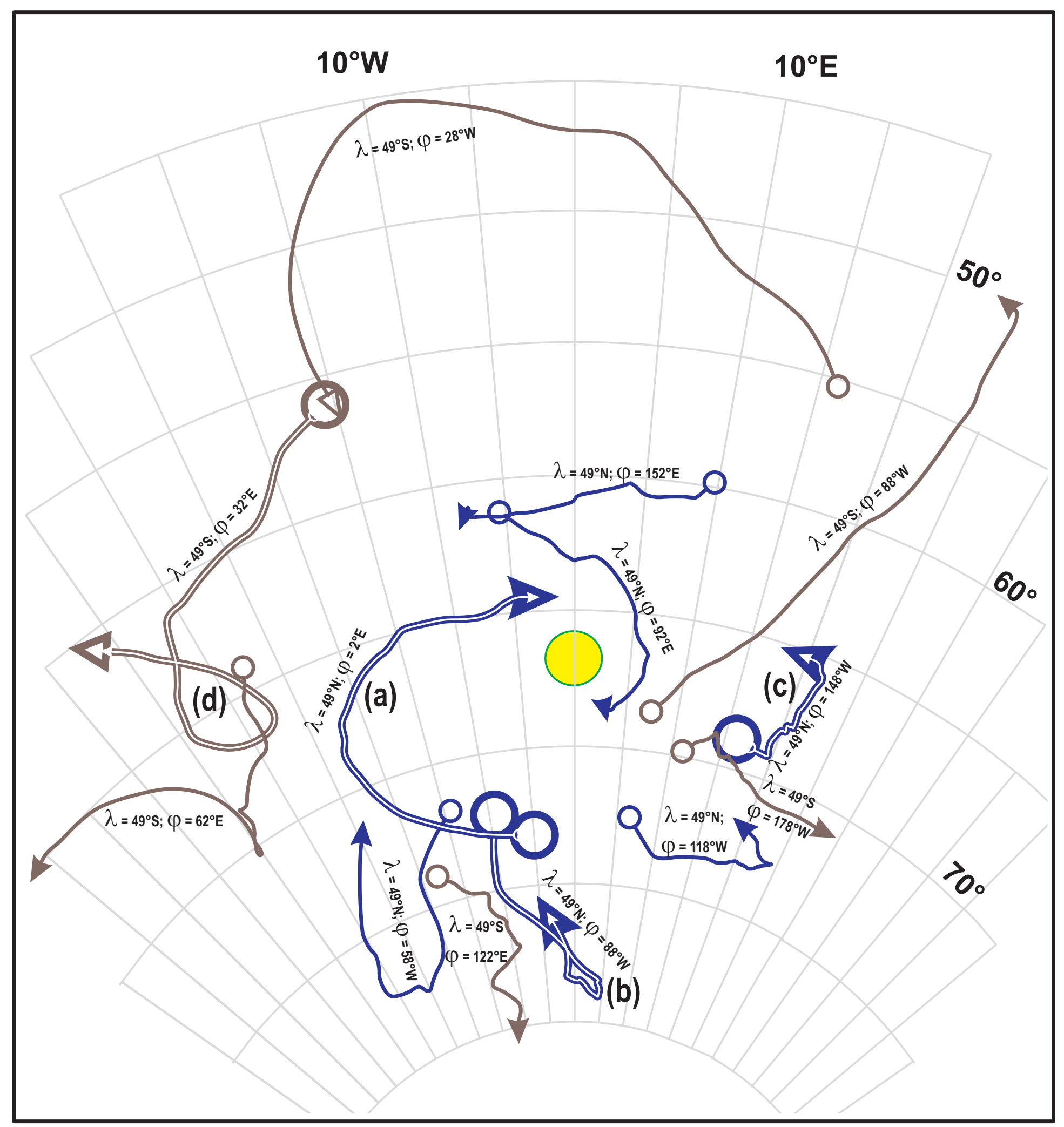

Figure 1 

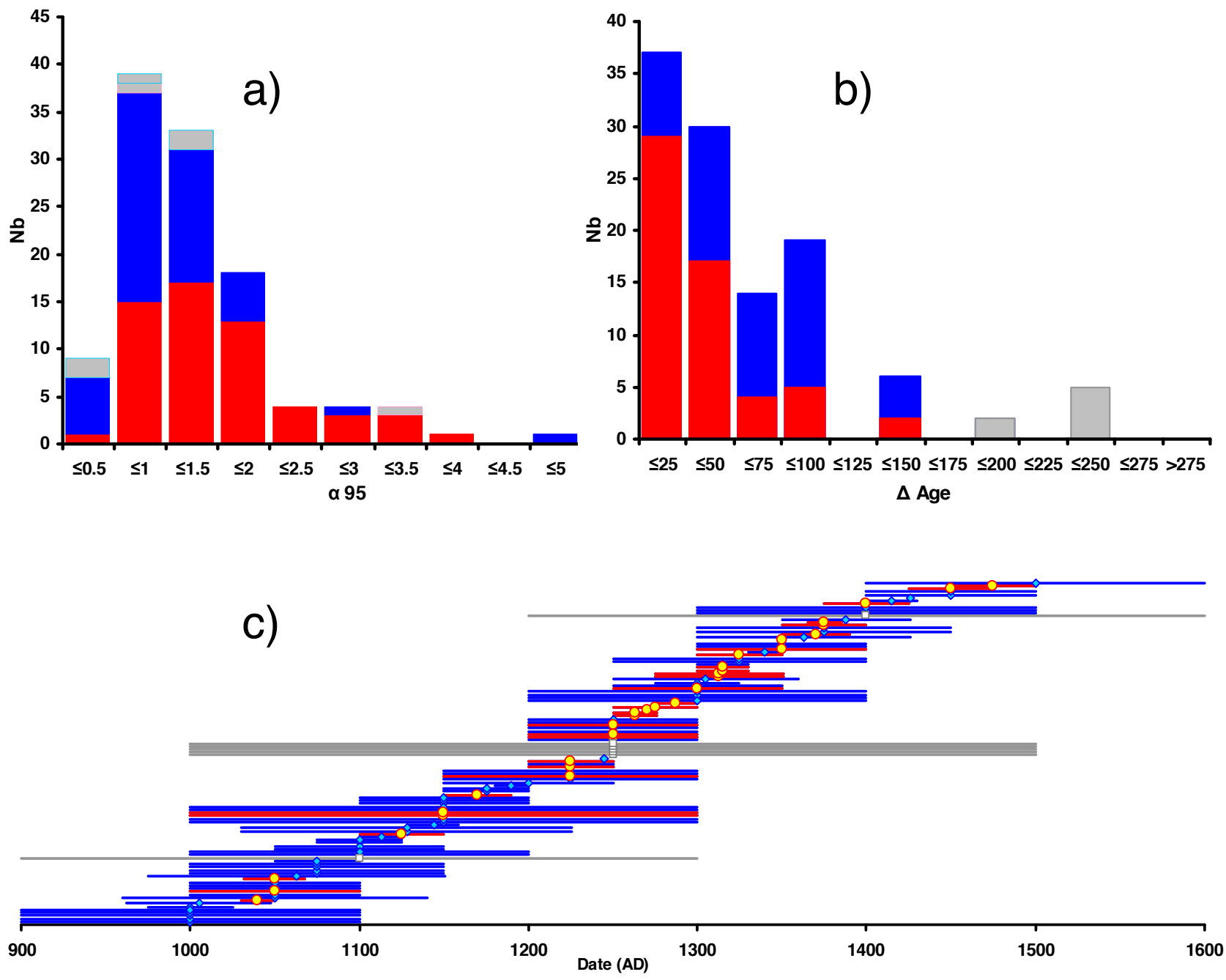

Figure 2 

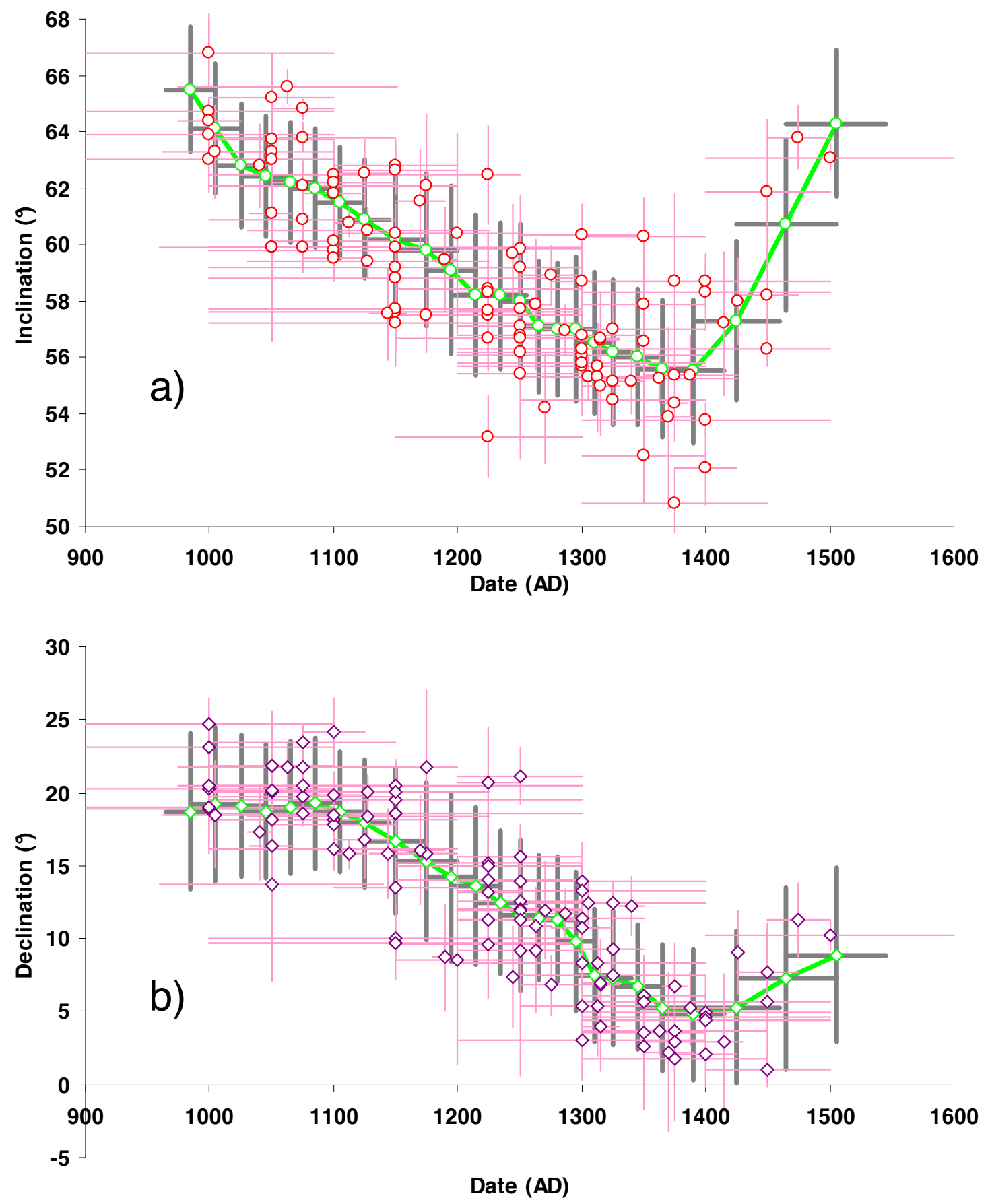

Figure 3 


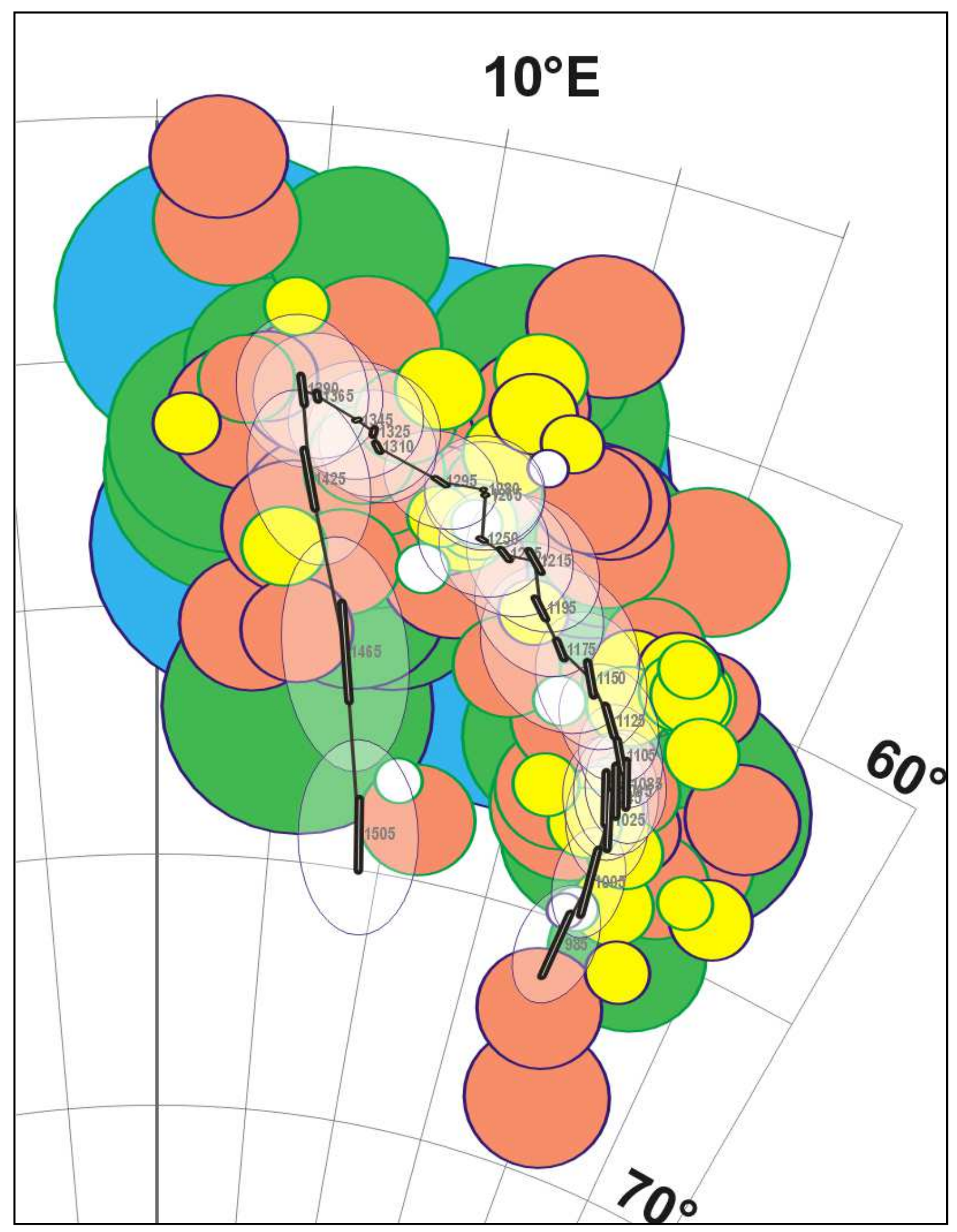

Figure 4 


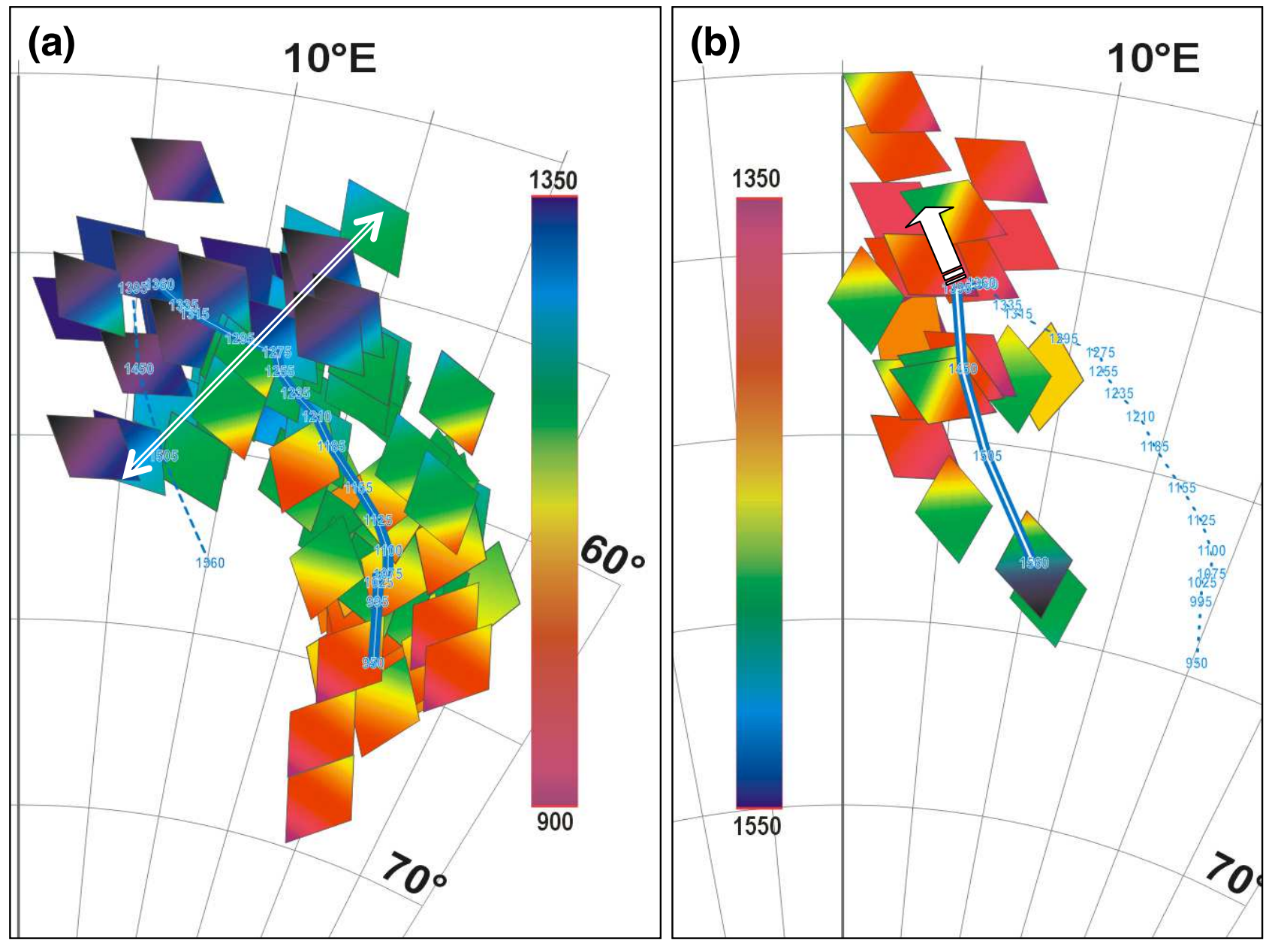

Figure 5 


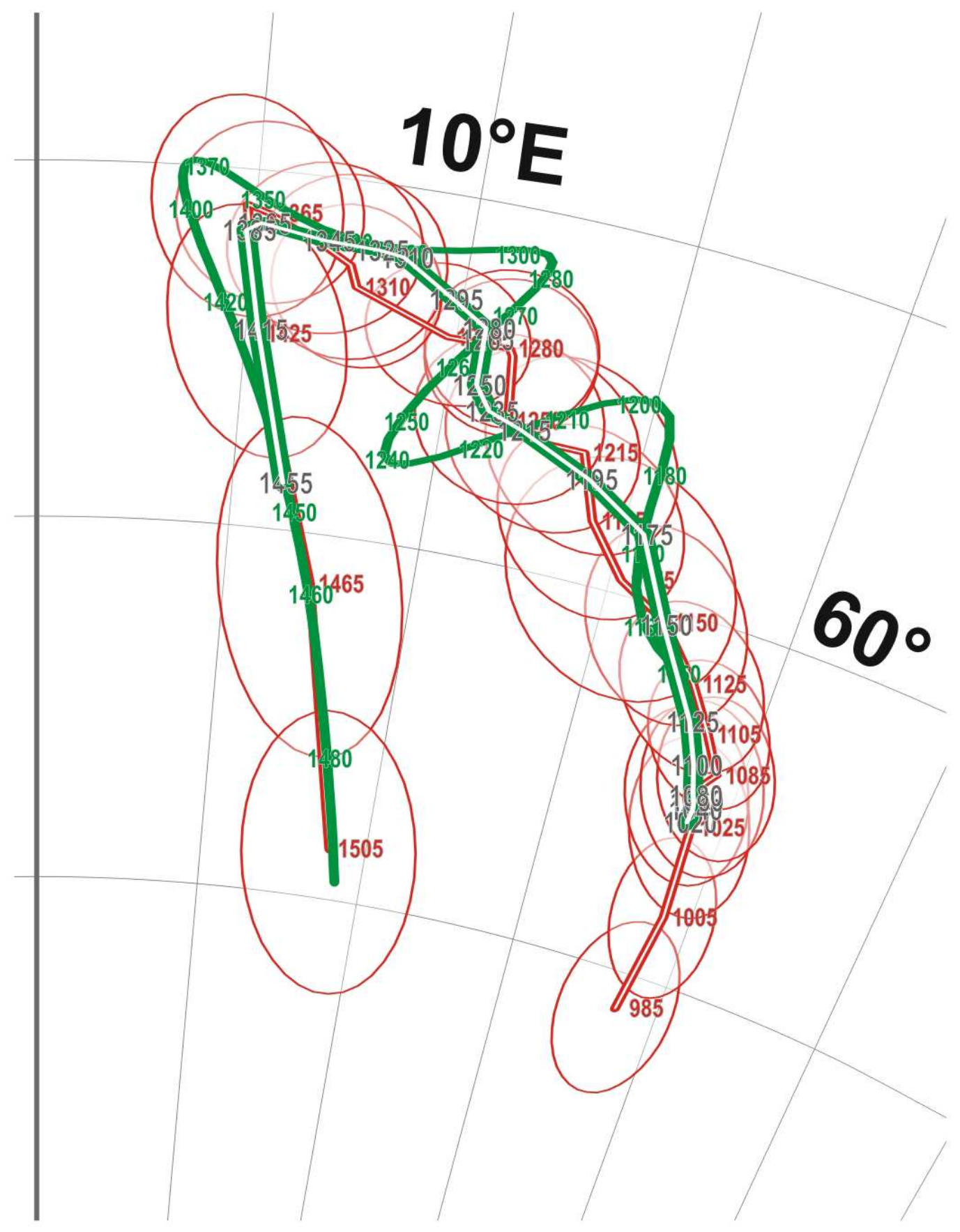

Figure 6 

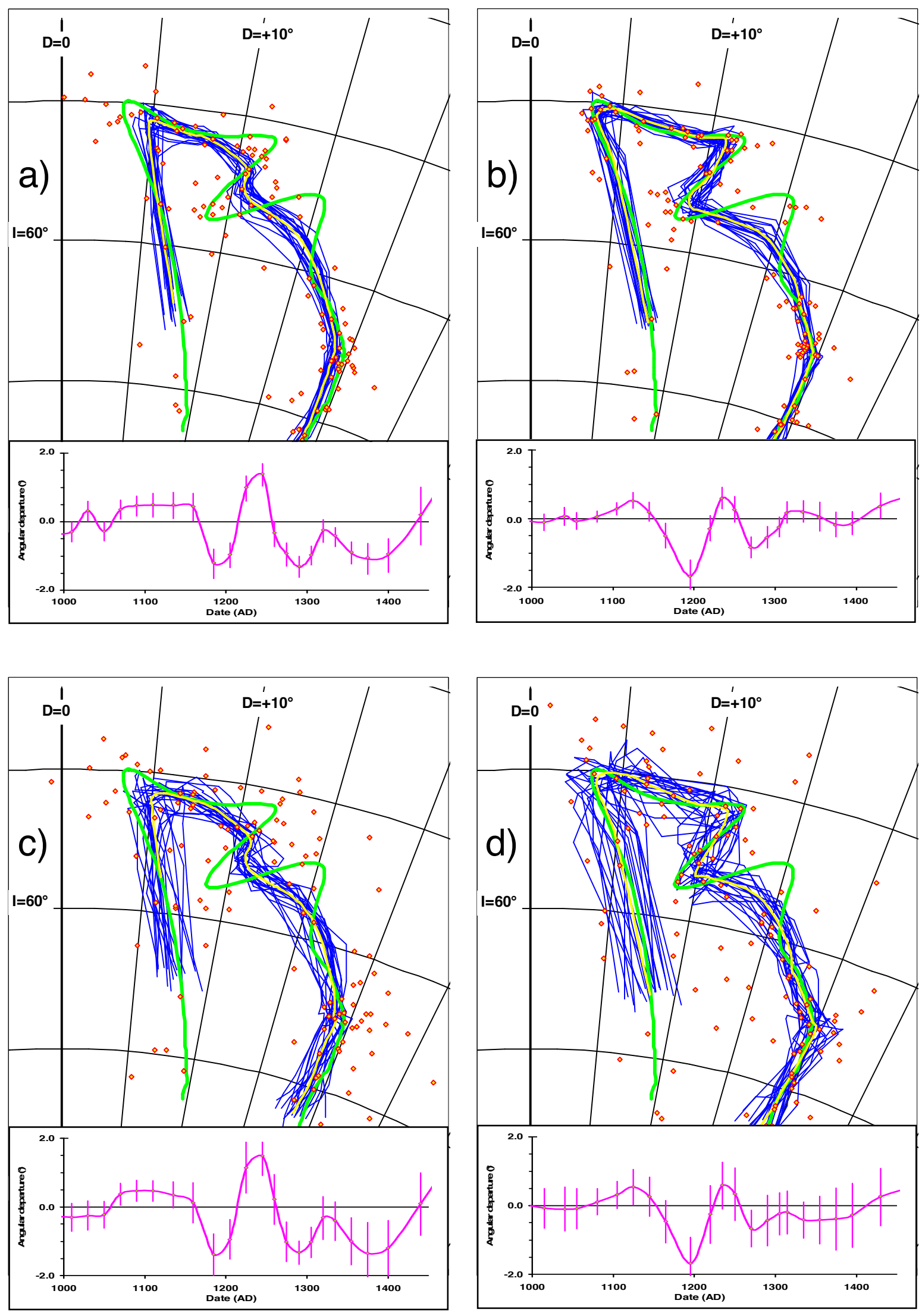

Figure 7 


$$
\frac{A B}{A B}
$$



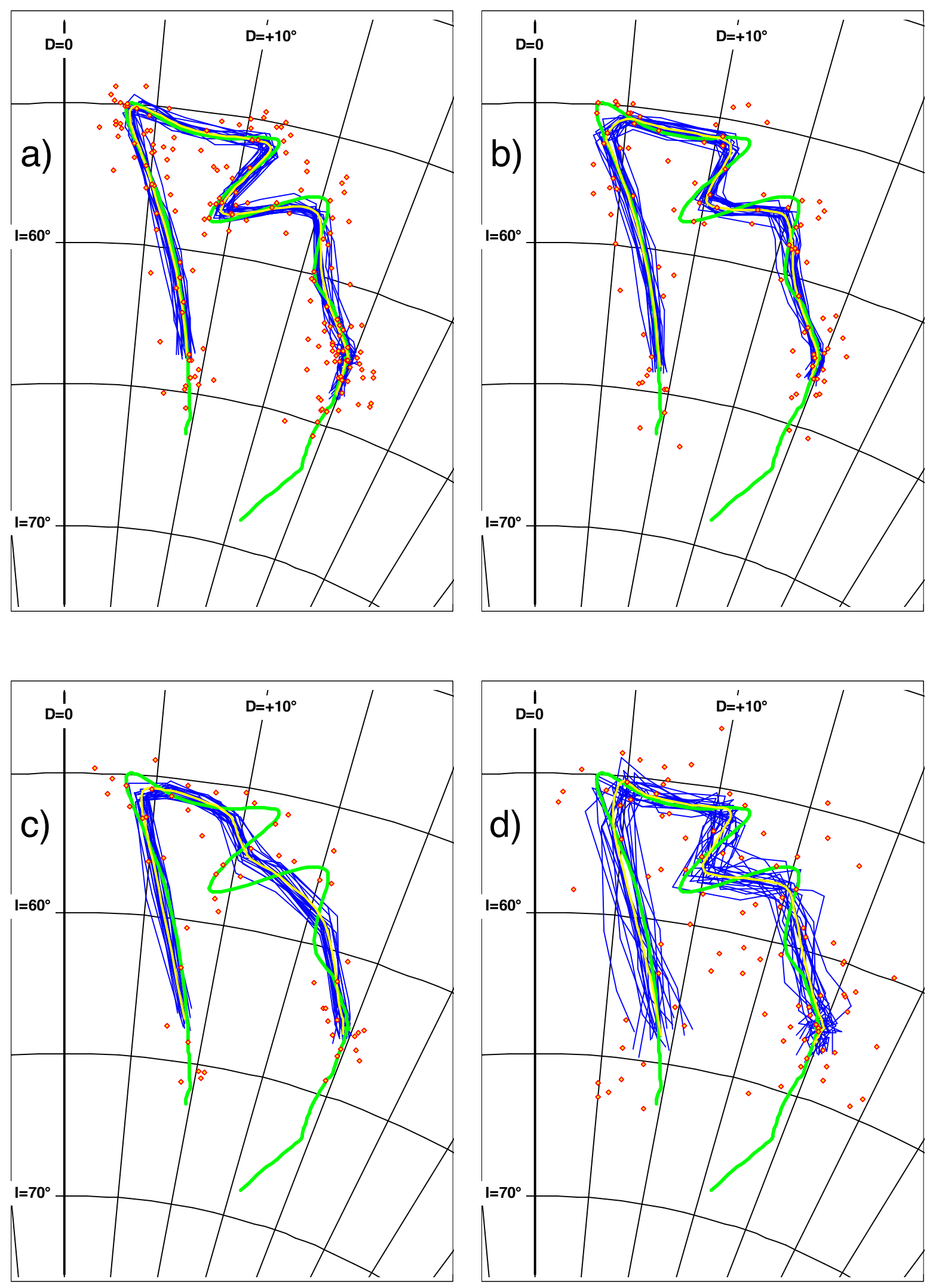

Figure 9 

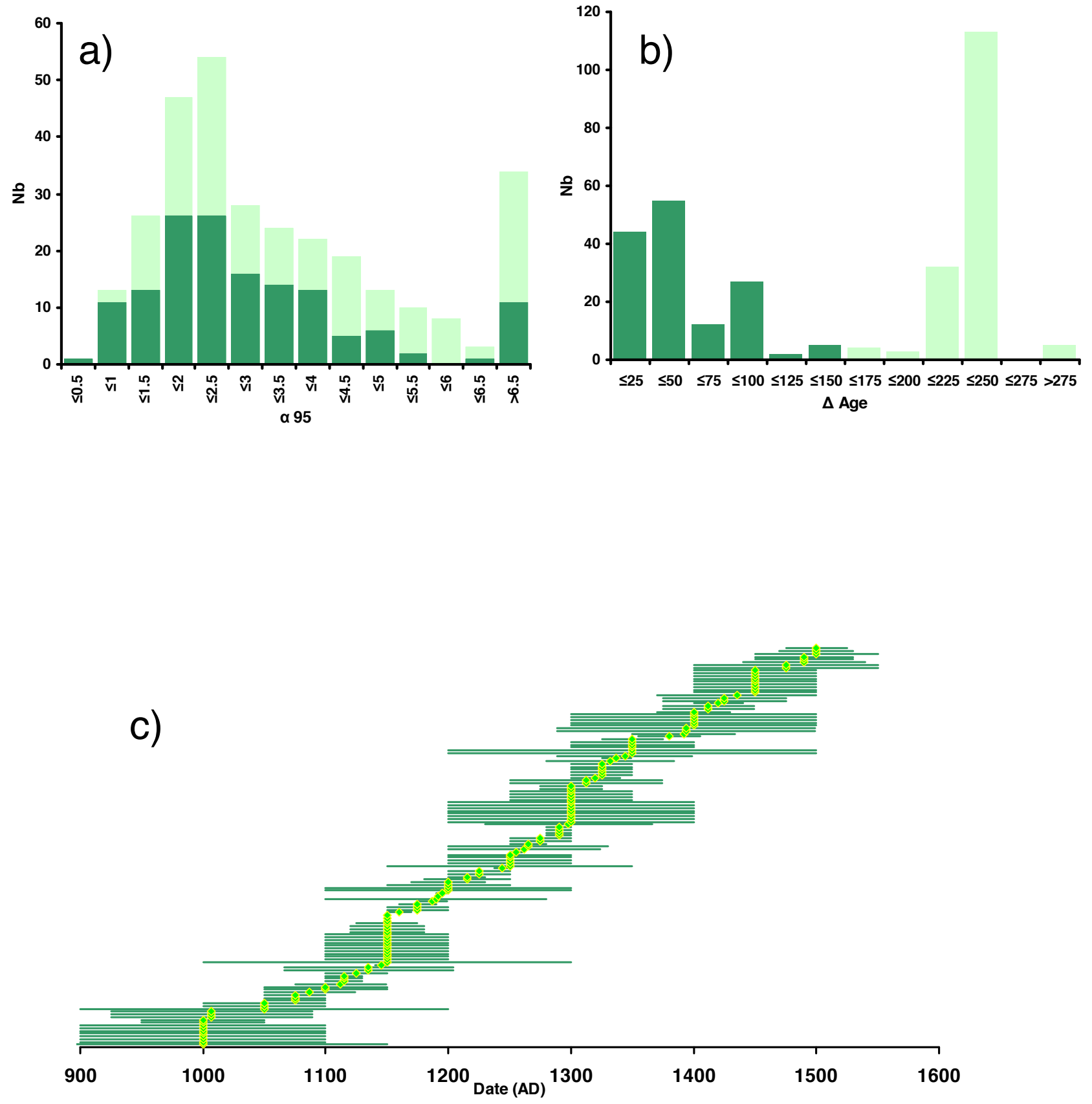

Figure S1 

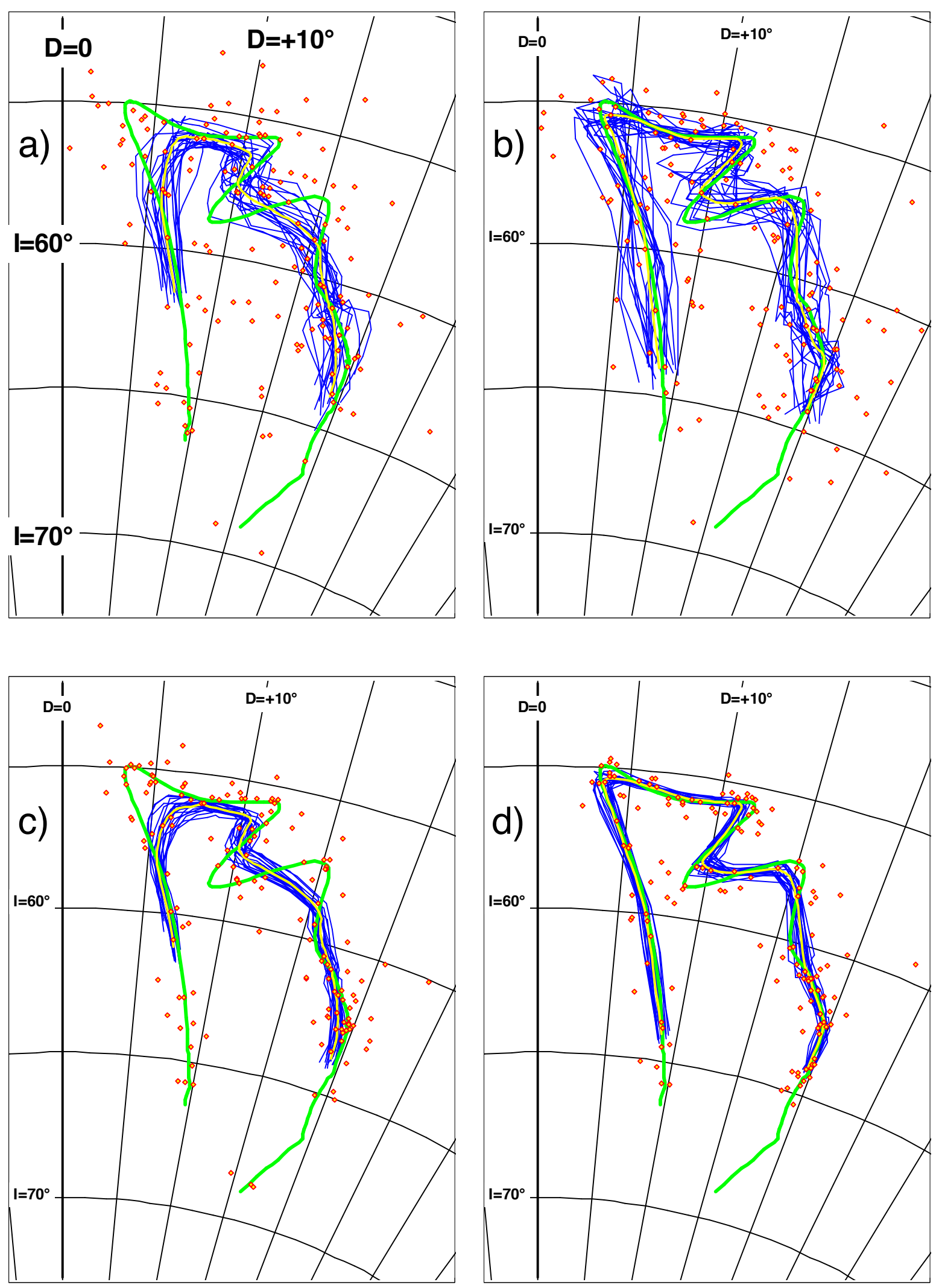

Figure S2 